\title{
Aa. Vv., Modernité du vers, «Romantisme» n. 140
}

\section{Ida Merello}

\section{(Q) OpenEdition}

\section{Journals}

\section{Edizione digitale}

URL: http://journals.openedition.org/studifrancesi/8333

DOI: 10.4000/studifrancesi.8333

ISSN: 2427-5856

\section{Editore}

Rosenberg \& Sellier

\section{Edizione cartacea}

Data di pubblicazione: 1 mai 2009

Paginazione: 200-201

ISSN: 0039-2944

\section{Notizia bibliografica digitale}

Ida Merello, «Aa. Vv., Modernité du vers, «Romantisme» n. 140», Studi Francesi [Online], 157 (LIII | I) |

2009, online dal 30 novembre 2015, consultato il 13 janvier 2021. URL: http://

journals.openedition.org/studifrancesi/8333 ; DOI: https://doi.org/10.4000/studifrancesi.8333

Questo documento è stato generato automaticamente il 13 janvier 2021.

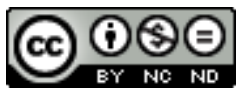

Studi Francesi è distribuita con Licenza Creative Commons Attribuzione - Non commerciale - Non opere derivate 4.0 Internazionale. 


\title{
Aa. Vv., Modernité du vers, «Romantisme» n. 140
}

\author{
Ida Merello
}

\section{NOTIZIA}

Modernité du vers, «Romantisme» n. 140, 2008.

$1 \quad$ Numero di grande compattezza, prende le mosse da una riflessione sull'influenza della versificazione scolastica sulla creazione poetica, che ha condotto da un lato a una grande abitudine di composizione, spesso di natura occasionale, abituale nelle feste e nelle occasioni politiche e mondane, dall'altro all'insofferenza per la metrica tradizionale fino all'esplosione del verso libero. corinne LEGOY segnala che fino al 1830 la produzione poetica era superiore a quella narrativa, Brigitte BUFFARD MOURET si sofferma invece sulla volontà di sperimentare nuovi metri su sollecitazione di un gusto troubadour cui non si accompagnava in realtà un'autentica conoscenza della poesia medievale, ma che suggeriva comunque l'uso di forme desuete, come la terzina. Ricorda inoltre come tale ricerca si estendesse alle forme poetiche orientali, quali il ben noto pantoum, o alle canzoni, che a loro volta suggerivano l'uso di versi brevi e impari, con grande insistenza di ritornelli e omofonie. Benoît DE CORNULIER mostra invece la difficoltà di individuare il ritmo di un metro in maniera oggettiva, addentrandosi poi in una serrata analisi dei ritmi 6-6, 4-4-4, 3-5-4, verificandone la resa poetica in Verlaine, Rimbaud e Mallarmé, prima di chiudere su Les Aveugles di Baudelaire, sonetto regolare che si può però percepire, data la disposizione delle rime, come articolato in un'ottava e una sestina. L'A. mostra allora la consonanza tra l'architettura metrica e il contenuto. André VAILlant (Le lyrisme du vers syllabique: de Lamartine à Mallarmé, pp. 53-66) si sofferma invece sul concetto di lirismo. La plasticità formale del verso ha reso infatti possibile il manifestarsi delle diverse voci poetiche, ed è proprio il xIX secolo che, a partire dall'epoca romantica, ha sempre più approfondito la «signifiance» del verso sillabico, quale espressione autoriale. Tale «signifiance» spiegherebbe l'altrimenti 
ingiustificabile successo di Lamartine: l'A. cita Le Lac come esempio dell'estetica lamartiniana, fondata sul principio di ripetizione esteso a tutti i livelli, tale da creare una serie di echi che sollecitano un ritorno a monte verso una voce primitiva. L'A. fa invece risalire a Hugo la nascita del verso moderno: verso che poggia sulla parola più che sulla frase e dove è costantemente sottolineato il rapporto antifrastico tra grammatica e prosodia per far risaltare la ricerca della «forme optique de la pensée». In tal modo Hugo esibiva l'autonomia del soggetto lirico: Baudelaire invece, pur mettendo ugualmente al centro della riflessione il rapporto tra l'io e il mondo, lo risolveva in dissidio, opponendo al mondo una perfezione formale che non deriva più da un principio esterno bensì da un'esigenza interiore. L'A. conclude perciò che il verso è «aspiré dans la sphère du sujet»: la forma gelificata diventa perciò l'espressione ironica di un'intenzione d'autore; per questo Vaillant può usare l'espressione di «lyrisme antilyrique». Il saggio si conclude sulla poesia di Rimbaud e Mallarmé. Rimbaud radicalizza il programma di Hugo, dislocando l'alessandrino fino ad ucciderlo ed accompagnando quest'operazione da un'equivalente radicalizzazione delle figure e dei fonemi. Per Rimbaud l'ordine non può che essere un'imposizione politica soffocante: la sua poesia si regge sul difficile equilibrio tra rifiuto e adesione. Al contrario Mallarmé vede nelle innovazioni del verso libero un modo per rinfrescare la prosodia tradizionale, rimotivandola. La rigida scansione metrica si accompagna a una sintassi sconvolta, che richiede la complicità del lettore, sollecitato a svelare il progetto autoriale.

2 Steve MURPHY (Versifications «parnassiennes» (?), pp. 67-84) ritorna sulla questione che già Badesco aveva affrontato negli anni Sessanta sulla mancanza di unità del cosiddetto «Parnasse», in realtà dai confini porosi, dove rientrano anche Baudelaire e Hugo. Dal punto di vista invece dell'impiego di caratteristiche forme metriche, i confini rendono ancora più incerta la specificità del movimento, in quanto triolets e rondeaux erano stati già rimessi in auge dai romantici. Se appare futile quindi opporre la versificazione parnassiana alla romantica, l'A. mostra inoltre come le posizioni estetiche di Banville siano assai vicine a quelle di Baudelaire (e di Poe) e come i parnassiani abbiano proseguito la sperimentazione degli anni Venti. La vera cesura è riconosciuta dall'A. solo con la rivoluzione di Rimbaud.

3 solenn DUPAS (Poétique et politique de l'allégorie en vers, pp. 85-98) ricorda come Verlaine fosse politicamente schierato, e per questo ripropone la poesia Le Monstre, uscita il 28 settembre su «Le Nain jaune», che rivela procedimenti già in atto nei Poèmes saturniens, come l'appropriazione di un bestiario simbolico antibonapartista. L'A. paragona il procedimento di Verlaine a quello dei caricaturisti come Daumier, Grandville o Gill, per cui certi particolari anatomici dei volti rimandano più facilmente a una forma zoomorfa, connotata negativamente nella tradizione simbolica. Ad esempio i baffi dell'imperatore sono assimilati alle antenne dell'astice, considerato impuro perché si nutre di resti di pesci morti. Verlaine sostituisce il «rêveur sacré hugoliano» con un «rêveur terrorisé», grazie a un'interiorizzazione del processo allegorico.

christine LOMBEZ (La traduction poétique et le vers français au XIX siècle, pp. 99-110) cerca i primi esempi di versi liberi nelle traduzioni poetiche degli anni Venti dell'Ottocento. Così Elise Voïart traduce Fridolin di Schiller in versi liberi, Amiel La cloche, sempre di Schiller; mentre la traduzione quanto mai libera dei testi poetici in canti era considerata del tutto normale. Negli anni Sessanta André van Hasselt e Amiel traducono Le roi des aulnes messo in musica da Schubert dal poema di Goethe, prendendosi numerose licenze poetiche, ma soprattutto mostrando il tentativo di 
adeguare ritmicamente il verso francese. Sono pertanto i traduttori, osserva l'A., quando scrivono in proprio, che considerano normali una serie di libertà già acquisite in sede traduttiva.

5 Michel Murat (L'oubli de Laforgue, pp. 111-123) isola i fenomeni che hanno presieduto alla nascita del verso libero e del poème en prose: 1) un insieme di condizioni preventive; 2) un fenomeno di cristallizzazione; 3) il ruolo delle circostanze. La creazione di una forma è infatti spesso una valorizzazione di quanto, già esistente, non è ancora emerso. Diventano perciò elementi fondamentali la presenza di un corpus di riferimento (tra cui l'omaggio di Baudelaire a Aloysius Bertrand), un gesto creatore che fissa le regole del gioco prima ancora che sia elaborata una teoria (il commento di Laforgue sui versi liberi in una lettera a Kahn), la presenza di un grande numero di poeti di origine straniera attivi nel periodo, oltre all'effervescenza della giovinezza di Rimbaud. L'A. ricorda l'importanza teorica di Kahn; mentre vede nell'operazione di frammentazione dei versi operata da Krysinska nella riedizione dei componimenti apparsi sullo «Chat noir» la dimostrazione di un'aspettativa di poesia e non di prosa. La corrispondenza tra Laforgue e Kahn mostra proprio la necessità da parte di Laforgue di trovare un'alternativa alla poesia versificata, attraverso lo sfruttamento delle risorse di un nuovo stile e alle diverse possibilità combinatorie, nella sempre grande attenzione alla disposizione grafica. 